\title{
Co-localisation and secretion of glucagon-like peptide 1 and peptide $Y Y$ from primary cultured human $L$ cells
}

\author{
A. M. Habib - P. Richards • G. J. Rogers • F. Reimann • F. M. Gribble
}

Received: 21 December 2012 / Accepted: 21 February 2013 /Published online: 22 March 2013

(C) The Author(s) 2013. This article is published with open access at Springerlink.com

\begin{abstract}
Aims/hypothesis Targeting the secretion of gut peptides such as glucagon-like peptide 1 (GLP-1) and peptide YY (PYY) is a strategy under development for the treatment of diabetes and obesity, aiming to mimic the beneficial alterations in intestinal physiology that follow gastric bypass surgery. In vitro systems are now well established for studying the mouse enteroendocrine system, but whether these accurately model the human gut remains unclear. The aim of this study was to establish and characterise human primary intestinal cultures as a model for assessing GLP-1 and PYY secretion in vitro.

Methods Fresh surgical biopsies of human colon were digested with collagenase to generate primary cultures from which GLP-1 and PYY secretion were assayed in response to test stimuli. GLP-1 and PYY co-localisation were assessed by flow cytometry and immunofluorescence microscopy.

Results GLP-1 and PYY were found localised in the same cells and the same secretory vesicles in human colonic tissue samples. GLP-1 release was increased to 2.6-fold the control value by forskolin+isobutylmethylxanthine $(10 \mu \mathrm{mol} / 1$ each), 2.8-fold by phorbol myristate acetate $(1 \mu \mathrm{mol} / \mathrm{l})$ and 1.4 -fold by linoleic acid $(100 \mu \mathrm{mol} / \mathrm{l})$. PYY release was increased to 2.0-, 1.8- and 1.3-fold by the same stimuli, respectively. Agonists of G-protein-coupled receptor (GPR)40/120 and G-protein-coupled bile acid receptor 1 (GPBAR1) each increased GLP-1 release to 1.5 -fold, but a GPR119 agonist did not significantly stimulate secretion.
\end{abstract}

\footnotetext{
A. M. Habib · P. Richards • G. J. Rogers • F. Reimann $(\bowtie)$

F. M. Gribble $(\square)$

Cambridge Institute for Medical Research, Addenbrooke's

Hospital Box 139, Hills Road,

Cambridge CB2 0XY, UK

e-mail: fr222@cam.ac.uk

e-mail: fmg23@cam.ac.uk
}

Conclusions/interpretation Primary human colonic cultures provide an in vitro model for interrogating the human enteroendocrine system, and co-secrete GLP-1 and PYY. We found no evidence of PYY-specific cells not producing GLP-1. GLP-1 secretion was enhanced by small molecule agonists of GPR40/120 and GPBAR1.

Keywords FFAR1 - GLP-1 · Glucagon-like peptide 1 . GPBAR1 · GPR119 · GPR120 · GPR40 · Human primary culture $\cdot$ Peptide YY · TGR5

$\begin{array}{ll}\text { Abbreviations } \\ \text { FFAR1 } & \text { Free fatty acid receptor 1 } \\ \text { FSK } & \text { Forskolin } \\ \text { GLP-1 } & \text { Glucagon-like peptide 1 } \\ \text { GPBAR1 } & \text { G-protein-coupled bile acid receptor 1 } \\ \text { GPR } & \text { G-protein-coupled receptor } \\ \text { IBMX } & \text { Isobutylmethylxanthine } \\ \text { PMA } & \text { Phorbol myristate acetate } \\ \text { PYY } & \text { Peptide YY }\end{array}$

\section{Introduction}

The intestinal epithelium produces a variety of hormones that enhance insulin release and satiety. Among these, glucagon-like peptide 1 (GLP-1) has received attention for its ability to increase glucose-dependent insulin release and reduce food intake, and these properties have been harnessed in the form of GLP-1 mimetics and dipeptidyl peptidase 4 inhibitors for the treatment of type 2 diabetes [1]. The mechanisms underlying its secretion have recently been characterised using a range of murine in vitro systems [2], but equivalent data are currently lacking for humans.

GLP-1 is secreted by entero-endocrine L cells found scattered in the intestinal epithelium. L cells increase in 
density along the proximal-distal gut axis. In addition, they exhibit longitudinal variation in the spectrum of hormones found co-localised with GLP-1. We recently reported that, in the mouse gut, a high proportion of $\mathrm{L}$ cells in the upper small intestine produce cholecystokinin, whereas the percentage of $L$ cells containing the anorectic hormone peptide YY (PYY) increases progressively towards the colon [3]. Despite the findings that PYY is predominantly co-located with GLP-1 in the mouse gut and that plasma levels of both PYY and GLP-1 rise after a meal, there seem to be some conditions that favour release of one hormone over the other [4]. Whether this is due to the activation of different $\mathrm{L}$ cell pools, the differential release of PYY and GLP-1 from the same secretory L cells or the existence of PYY-positive but GLP-1-negative cells, remains to be established.

In view of the production by $\mathrm{L}$ cells of a number of peptides that reduce appetite and lower plasma glucose, the idea of targeting this cell population for the treatment of diabetes and obesity is an area of therapeutic development. There are ongoing clinical and preclinical trials of a number of agents that activate L cell-specific G-proteincoupled receptors, such as the long-chain NEFA receptors (free fatty acid receptor 1 [FFAR1], G-protein-coupled receptor [GPR]120, GPR119) and the bile acid receptor G-proteincoupled bile acid receptor 1 (GPBAR1, also referred to as TGR5). Whether this strategy will work in humans remains to be definitively established, but the idea is supported by an increasing body of evidence that the gut endocrine system underlies many of the beneficial effects of gastric bypass on glycaemia and appetite [5]. In vitro models for the human L cell are critically needed, and the aims of this study were to devise methods to maintain human $\mathrm{L}$ cells in primary culture and to examine the effects of different G-protein-coupled receptor agonists on GLP-1 and PYY release.

\section{Methods}

Primary culture The study was approved by the local research ethics committee. Fresh anonymised surgical specimens of human colon were obtained from Tissue Bank at Addenbrooke's Hospital, Cambridge, stored at $4{ }^{\circ} \mathrm{C}$ and processed within hours of surgery. Tissue samples $(\sim 0.5 \mathrm{~g}$ in weight) were dissected free of muscle and connective tissue, rinsed, minced and digested four times (20 min each) with collagenase XI $(0.5 \mathrm{mg} / \mathrm{ml})$ in DMEM ( $4.5 \mathrm{~g} /$ glucose $)$ at $37^{\circ} \mathrm{C}$. Supernatant fractions from each digest were centrifuged twice at $100 \mathrm{~g}$ for $3 \mathrm{~min}$ to pellet crypts, which were resuspended in $7 \mathrm{ml}$ culture medium (DMEM supplemented with $10 \%$ (vol./vol.) fetal bovine serum, $2 \mathrm{mmol} / 1 \mathrm{~L}$-glutamine, $100 \mathrm{units} / \mathrm{ml}$ penicillin and $0.1 \mathrm{mg} / \mathrm{ml}$ streptomycin). Aliquots $(250 \mu \mathrm{l})$ were plated into 24 -well plates or glass coverslips coated thinly with Matrigel (BD Bioscience, Oxford, UK). During overnight incubation at $37^{\circ} \mathrm{C}$ in $5 \% \mathrm{CO}_{2}$, cells spread out to form a partial monolayer, similar in appearance to cultures from mouse colon that typically remain viable for up to 10 days [6].

Immunostaining After $16 \mathrm{~h}$ in culture, cells were fixed in 4\% (wt./vol.) paraformaldehyde, washed three times with PBS, and blocked in a solution of 5\% (vol./vol.) goat serum, $0.1 \%$ (vol./vol.) Triton X-100 in PBS for 30 min. Samples were incubated with guinea pig anti-PYY antibody $(1: 100$; catalogue number 16066; Progen, London, UK;) and rabbit anti-proglucagon antibody (1:200; catalogue number sc13091; Santa Cruz, CA, USA) for $3 \mathrm{~h}$ at room temperature,
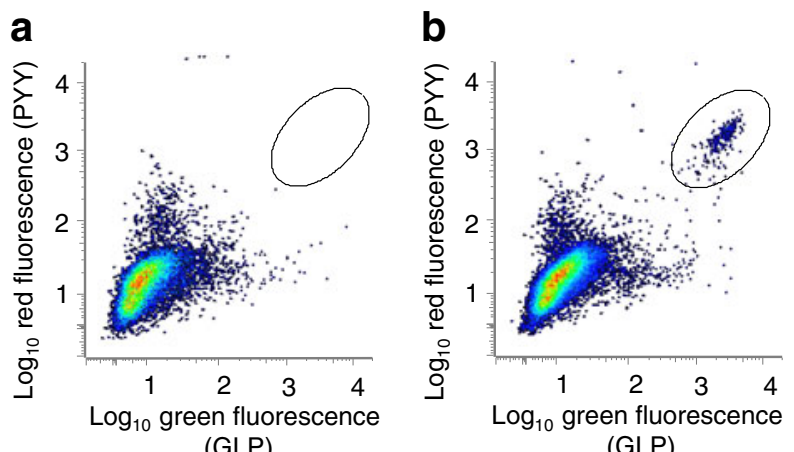

(GLP)
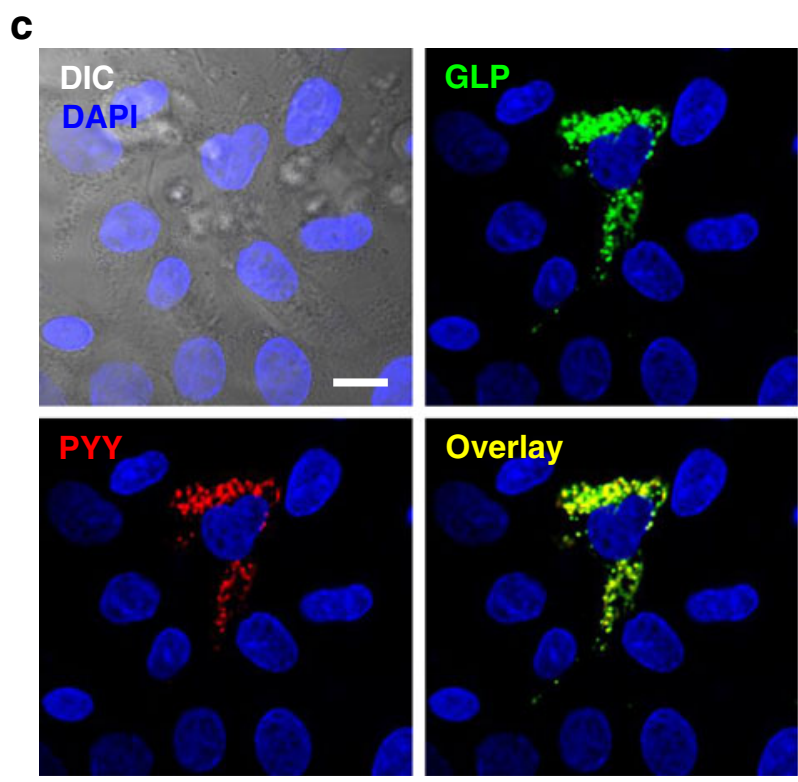

Fig. 1 Co-localisation of GLP-1 and PYY in human colonic L cells. (a,b) Paraformaldehyde-fixed colonic cell suspensions analysed by flow cytometry. Points in (b) depict the staining of individual cells for GLP ( $x$-axis) vs PYY ( $y$-axis). Both primary antibodies were omitted in the control (a). The position of double-positive cells is delineated by the oval. (c) The 16-h-old cultures were co-stained with primary antibodies to PYY (red) and GLP (green). Co-localisation of PYY and GLP immunofluorescence in a single L cell is shown (overlay, yellow). Nuclei were visualised with DAPI (blue). Images were captured using a $\times 63$ objective lens. The scale bar represents $10 \mu \mathrm{m}$ 
washed three times with $5 \%$ goat serum in PBS, and then incubated with Alexa-Fluor 633 anti-guinea pig and AlexaFluor 488 anti-rabbit antibodies (1:300 each; Invitrogen, Carlsbad, CA, USA) for a further hour. Control staining was performed by omitting proglucagon and/or PYY primary antibodies.

Flow cytometry Colonic biopsies were stripped of connective tissue, minced and digested twice with $1.25 \mathrm{mg} / \mathrm{ml}$ collagenase (type XI) in Hanks' buffered salt solution for $30 \mathrm{~min}$ at $37^{\circ} \mathrm{C}$. After gentle trituration using a $10 \mathrm{ml}$ pipette and filtering, the resultant single-cell suspension was fixed with $4 \%$ (wt./vol.) paraformaldehyde in PBS for $30 \mathrm{~min}$ at room temperature. Cell suspensions were incubated overnight in PBS- $10 \%$ (vol./vol.) goat serum at $4{ }^{\circ} \mathrm{C}$ and permeabilised with $10 \%$ goat serum, $0.3 \%$ Triton $\mathrm{X}-100$ in PBS. Pellets were incubated in PBS- $10 \%$ goat serum with/without proglucagon (1:200) and PYY (1:100) primary antibodies (as above) for $1 \mathrm{~h}$. Cells were rinsed three times in PBS-10\% goat serum and then incubated with secondary antibodies (as above; 1:1,000) for $30 \mathrm{~min}$. After three further washes, cells were analysed using a BD LSRFortessa analyser (BD Biosciences, San Jose, CA, USA) equipped with 488 and $640 \mathrm{~nm}$ lasers. Data were analysed using FlowJo 7.6 software (Tree Star, Ashland, OR, USA).

GLP-1 and PYY secretion Cultures were incubated with test reagents in saline buffer containing (in mmol/l) $4.5 \mathrm{KCl}, 138$ $\mathrm{NaCl}, 4.2 \mathrm{NaHCO}_{3}, 1.2 \mathrm{NaH}_{2} \mathrm{PO}_{4}, 2.6 \mathrm{CaCl}_{2}, 1.2 \mathrm{MgCl}_{2}$, 10 HEPES and 10 glucose $(\mathrm{pH} 7.4, \mathrm{NaOH})$ plus $0.1 \%$ fatty acid-free BSA, for $2 \mathrm{~h}$ at $37^{\circ} \mathrm{C}$. At the end of the incubation, cells were lysed with buffer containing: $50 \mathrm{mmol} / \mathrm{l}$ Tris$\mathrm{HCl}, 150 \mathrm{mmol} / \mathrm{l} \mathrm{NaCl}, 1 \%$ (vol./vol.) IGEPAL CA-630, $0.5 \%$ (wt./vol.) deoxycholic acid and one tablet of protease inhibitor cocktail (Roche Diagnostics, Burgess Hill, UK), and mechanically disrupted to extract intracellular peptides. Supernatants and lysates were assayed for active GLP-1 and/or total PYY by ELISA (Millipore, USA). Hormone secretion was expressed as a fraction of the total hormone content per well, normalised to basal secretion measured in parallel control wells. Forskolin (FSK, $10 \mu \mathrm{mol}$ ), isobutylmethylxanthine (IBMX, $10 \mu \mathrm{mol} / \mathrm{l}$ ), phorbol myristate acetate (PMA, $1 \mu \mathrm{mol} / \mathrm{l})$, GW9508 $(100 \mu \mathrm{mol} / \mathrm{l})$, AR231453 (10 nmol/l) and GPBAR1-A (3 $\mu \mathrm{mol} / \mathrm{l}$; Roche, Basel), were added from 1,000x stocks in DMSO. GW9508 and AR231453 were synthesised by AstraZeneca (Macclesfield, UK) and supplied as a kind gift. Linoleic acid was applied at $100 \mu \mathrm{mol} / \mathrm{l}$ from a $5 \mathrm{mmol} / \mathrm{l}$ stock prepared in saline buffer $+5 \%$ (wt/vol.) BSA. All chemicals were obtained from Sigma (Poole, UK), unless otherwise stated.

Statistical analysis One-sample Student's $t$ tests were performed using Microsoft Excel to test the null hypothesis that the data were from a population of mean $=1$. A $p$ value of less than 0.05 was considered significant.

\section{Results}

Co-localisation of GLP-1 and PYY in human colonic $L$ cells Dissociated human colonic biopsies were immunostained in suspension for GLP-1 and PYY and analysed by flow cytometry. A distinct population of double immunopositive cells, comprising $0.86 \pm 0.26 \%(n=4)$ of the total cell count, was evident in samples incubated with primary antibodies against GLP-1 and PYY (Fig. 1a,b). No significant populations were detected that were positive for only one of the two hormones.

Protocols were developed for the primary culture of human intestinal biopsies. In these mixed epithelial cultures
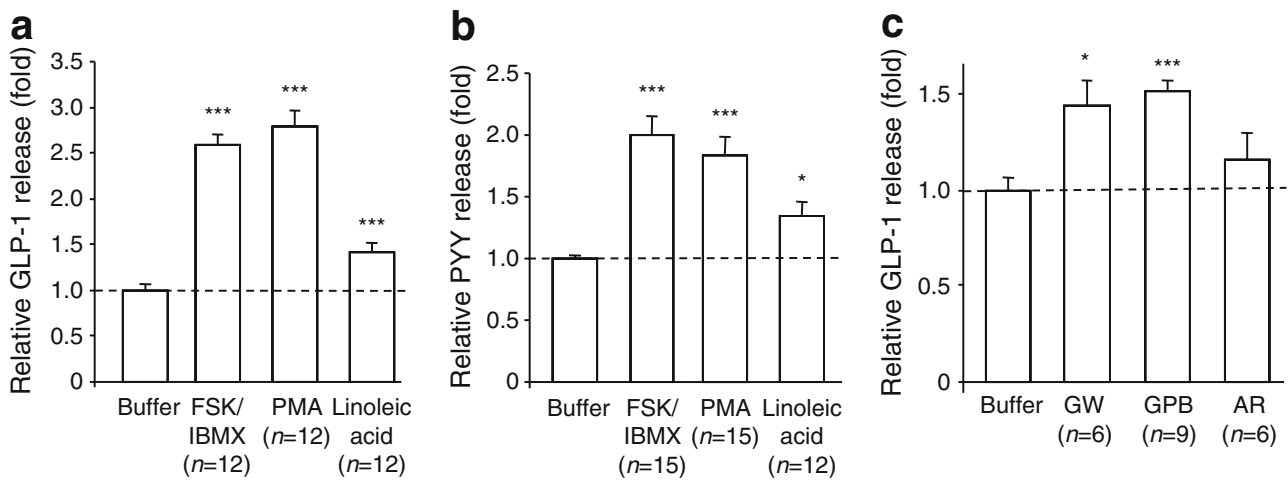

Fig. 2 GLP-1 and PYY secretion from primary human colonic cultures. The 1-day-old colonic cultures were incubated for $2 \mathrm{~h}$ in FSK+ $\operatorname{IBMX}(10 \mu \mathrm{mol} / 1$ each), PMA $(1 \mu \mathrm{mol} / 1)$ or linoleic acid $(100 \mu \mathrm{mol} / \mathrm{l})$. GLP-1 (a) and PYY (b) were assayed in the supernatant fraction and cell lysate to calculate the percentage of cell content released, and then normalised to the basal release measured in parallel control wells containing buffer with no additions. Error bars represent 1 SEM of the number of wells indicated. Mean basal GLP-1 and PYY release was $1.1 \pm 0.3 \%$ and $2.6 \pm 0.4 \%$, respectively, of the total cell content at 2 h. (c) Cultures were incubated with GW9508 (GW, $100 \mu \mathrm{mol} / \mathrm{l}$ ), GPBAR1-A (GPB, $3 \mu \mathrm{mol} / \mathrm{l}$ ) or AR231453 (AR, $10 \mathrm{nmol} / \mathrm{l}$ ), and assayed for GLP-1 as in (a). ${ }^{*} p<0.05,{ }^{* * *} p<0.001$ 
fixed with paraformaldehyde, L cells were readily identifiable by immunofluorescence. Consistent with the FACS results, GLP-1 and PYY were found localised in the same cells, and were detectable by confocal microscopy in the same secretory vesicles (Fig. 1c).

Co-secretion of GLP-1 and PYY from human colonic cultures To monitor the secretion of GLP-1 and PYY from primary human colonic cultures, cells were incubated for $2 \mathrm{~h}$ with test stimuli. GLP-1 release was enhanced to 2.6-fold the control value by FSK+IBMX, 2.8-fold by PMA and 1.4-fold by linoleic acid (Fig. 2a). PYY release mirrored the profile of GLP-1 secretion (Fig. 2b), consistent with the observed localisation of both peptides to the same cell and vesicle populations. GLP-1 responses to agonists of GPR40/120, GPR119 and GPBAR1 were also examined, using the compounds GW9508 [7], AR231453 [8] and GPBAR1-A [9], respectively. Stimulation of GPR40/120 and GPBAR1, but not GPR119, enhanced GLP-1 secretion (Fig. 2c).

\section{Discussion}

Human L cells survived in mixed primary colonic epithelial cultures and were activated by physiological stimuli. GLP-1 and PYY were co-localised in the same vesicle pools, as described previously [4], with no detectable cell population producing only one of the two peptides. Consistent with the strong co-localisation of the two peptides by FACS analysis and in primary cultures, both were released in parallel in secretion assays.

Surprisingly, the primary human cultures released GLP-1 in response to agonists of FFAR1/GPR120 and GPBAR1, but were not significantly activated by the GPR119 agonist AR231453. In comparative studies using mouse colonic cultures prepared with similar protocols, the same compounds/concentrations triggered GLP-1 release to 3.4-, 4.2- and 2.3-fold of control values, respectively (data not shown), and FSK+IBMX increased secretion $\sim 10$-fold [6]. Thus, across all stimuli, human cultures exhibited $\sim 4$-fold lower responsiveness than murine cultures, despite similar basal rates of secretion $(1.1 \pm 0.3 \%$ and $1.3 \pm 0.3 \%$ of the total GLP- 1 content per $2 \mathrm{~h}$, respectively). Whether this reflects a genuine difference in responsiveness between human vs mouse L cells, or is a consequence of the dissociation and culture conditions employed, cannot be established from our data. In the face of the lower general responsiveness of human than murine cultures, responses to weaker stimuli were less readily detectable, perhaps explaining the lack of a significant stimulation by AR231453 in this study. The possibility that GPR119 agonists may be relatively poor stimuli in the human colon should, however, be considered, in the light of some recent disappointing metabolic responses to GPR119 agonists in clinical trials [10].

Translating findings from mouse to human is a crucial step in drug development. The primary human intestinal cultures described here provide an in vitro system that should help to bridge this technological gap.

Funding This work was funded by Wellcome Trust grants to F. M. Gribble and F. Reimann (WT088357 and WT084210), and by a European Foundation of the Study of Diabetes (EFSD)/Amylin Paul Langerhans Grant.

Duality of interest The authors declare that there is no duality of interest associated with this manuscript.

Contribution statement AMH, GJR and PR designed and performed experiments. FR and FMG designed the study and drafted the manuscript. All authors contributed to critical revision of the manuscript and approved the final version.

Open AccessThis article is distributed under the terms of the Creative Commons Attribution Noncommercial License which permits any noncommercial use, distribution, and reproduction in any medium, provided the original author(s) and the source are credited.

\section{References}

1. Nauck MA (2011) Incretin-based therapies for type 2 diabetes mellitus: properties, functions, and clinical implications. Am J Med 124:S3-S18

2. Tolhurst G, Reimann F, Gribble FM (2012) Intestinal sensing of nutrients. Handb Exp Pharmacol 209:309-335

3. Habib AM, Richards P, Cairns LS et al (2012) Overlap of endocrine hormone expression in the mouse intestine revealed by transcriptional profiling and flow cytometry. Endocrinology 153:3054-3065

4. Nilsson O, Bilchik AJ, Goldenring JR, Ballantyne GH, Adrian TE, Modlin IM (1991) Distribution and immunocytochemical colocalization of peptide YY and enteroglucagon in endocrine cells of the rabbit colon. Endocrinology 129:139-148

5. Tam CS, Berthoud HR, Bueter M et al (2011) Could the mechanisms of bariatric surgery hold the key for novel therapies? Report from a Pennington Scientific Symposium. Obes Rev 12:984-994

6. Reimann F, Habib AM, Tolhurst G, Parker HE, Rogers GJ, Gribble FM (2008) Glucose sensing in L cells: a primary cell study. Cell Metabol 8:532-539

7. Briscoe CP, Peat AJ, McKeown SC et al (2006) Pharmacological regulation of insulin secretion in MIN6 cells through the fatty acid receptor GPR40: identification of agonist and antagonist small molecules. Br J Pharmacol 148:619-628

8. Chu ZL, Carroll C, Alfonso J et al (2008) A role for intestinal endocrine cell-expressed $\mathrm{G}$ protein-coupled receptor 119 in glycemic control by enhancing glucagon-like peptide- 1 and glucose-dependent insulinotropic peptide release. Endocrinology 149:2038-2047

9. Keitel V, Cupisti K, Ullmer C, Knoefel WT, Kubitz R, Häussinger D (2009) The membrane-bound bile acid receptor TGR5 is localized in the epithelium of human gallbladders. Hepatology 50:861-870

10. Katz LB, Gambale JJ, Rothenberg PL et al (2012) Effects of JNJ38431055 , a novel GPR119 receptor agonist, in randomized, double-blind, placebo-controlled studies in subjects with type 2 diabetes. Diabetes Obes Metabol 14:709-716 